\title{
DESIGN CRITERIA FOR NEIGHBOURHOOD LIFE QUALITIES - A CIVIL ENGINEERING EDUCATIONAL APPROACH
}

\author{
Rein Terje THORSTENSEN and Harald MARRABLE \\ University of Agder, Norway
}

\begin{abstract}
Housing represents the most significant inroad to the income for most households. Housing distinguish and safeguards the private from the public and defines private life. Major parts of life are also defined by the neighbourhood. It reflects social status and delivers or denies qualities in everyday life. Neighbourhoods can promote socialising and friendship, appear foreign or even isolate people in their homes. From the architectural and urban-architectural professions, it is well-known that physical design influences the qualities that might be perceived in the span from comforting to alienating. Yet, often little knowledge seems to be commonly available or utilised amongst professional property developers. Why is this?

Residential areas are often designed by civil engineers, having little knowledge of design. The ruling design criteria are often limited to a minimisation of cost and construction time, after complying with legal requirements. Characteristics and design criteria supporting living quality in neighbourhoods are not commonly taught in civil engineering education.

The focus of this paper is not on extending the knowledge about the interrelatedness between design criteria and neighbourhood qualities. However, the focus is on how to supply civil engineers through their education with awareness, ballast and skills on how to accommodate this interrelatedness and make a better-built environment. The discussion includes a presentation of an educational approach unusual for civil engineering, to raise awareness of social qualities in residential planning. One main concern visual observations and interviews with residents discussing their neighbourhood. The result is increased awareness and social responsibility amongst engineering students.
\end{abstract}

Keywords: Design criteria for residential areas, civil engineering education, annual student investigation.

\section{INTRODUCTION}

A residential area is more than streets and houses - it is also a small community. As planners, we have a social responsibility to make these areas the best achievable places to live for everyone. Residential areas should function practically in summer and winter, be visually appealing and be physically adapted to develop good neighbourly relationships. It is an ethical obligation for the planner to develop neighbourhoods to safe places where everyone can thrive, feel ownership, and identity; that is having social quality.

Knowledge on the interrelatedness between design criteria and neighbourhood qualities are easily available through practitioners and researchers within the architectural and urban architectural professions. This was fundamental already in the Bauhaus era starting before 1920 and has been continuously developed until today. The New Urbanism movement might serve as one example, focusing on "planning that advocates design-based strategies based on "traditional" urban forms to help arrest suburban sprawl and inner-city decline and to build and rebuild neighbourhoods, towns, and cities" [1].

Municipal plans place requirements on living areas, e.g., land exploitation, housing density, parking, playgrounds, and so forth. In Norway, residential areas are often planned by civil engineers who have little knowledge beyond these technical and legal matters. The plans meet the municipality's minimum requirements and are otherwise limited to minimising costs and construction time. Traditionally, civil engineering education focuses on teaching students the technical aspects of zoning. Zoning is a 
fundamental yet complex subject within area planning, with a clear preponderance of technical disciplines. Traditionally, civil engineering education focuses on teaching students' aspects like terrain management, overwater treatment, greenery, road design, building principles, and technical infrastructure. Furthermore, the students learn to design plans that meet specific statutory requirements and standards. From a civil engineer's technical point of view, "the softer" aspects may seem diffused and complicated. Since there are no standards of social quality, this field has traditionally been ignored or given low priority in teaching. Still, these are the qualities people seek when buying a home. It is also these qualities that can ensure greater resilience and sustainability when a crisis occurs. How can the traditional technically focused civil engineering education support the development of this intangible competence?

\section{THE EDUCATIONAL APPROACH}

A proper approach to supplying civil engineering students with relevant ballast to handle these "softer" aspects, should include a focus on the multidisciplinary nature of the topic. In the paper "Understanding characteristics of multidisciplinary collaboration" [2], presented at E\&PDE 2018, the authors found that "collaborating in multidisciplinary teams requires awareness of disciplinary boundaries, appreciation of disciplinary perspective, appreciation of non-disciplinary perspective, recognition of disciplinary limitations, interdisciplinary evaluation, and the ability to find common ground, reflexivity and integrative skill". These claims seem reasonable and are well-founded by literature. However, it is a major challenge to supply students of the already packed civil engineering curriculum with this additional competence. Overlooking the vast number of titles from recent papers addressing multidisciplinary in product design education, this challenge of adding further skills on to already packed curricula seems to be well-known in the Design Society.

A good starting point when aiming at doing something new is to look for role models who already did something related. However, when searching for relevant research literature on combinations of the terms "neighbourhood qualities" and "engineering education", the outcome is scarce. This confirms the experience of our own that civil engineering educations tend to focus on the more tangible assets of the technical skills. "Design, engineering, and construction for more sustainable infrastructure involve complex decisions with considerable risk and uncertainty", as worded by McWirther and Shealy [3] in one of the few papers identified, discussing a related topic. McWirther and Shealy argue that organisations like the Accreditation Board for Engineering and Technology, the American Council for Construction Education, and the American Society of Civil Engineers stress this need correspondingly and advises on a problem based, flipped-classroom approach to address transdisciplinary complexes. The paper discusses how students gain through a sequential assessment programme, first focusing on technical issues like cost and flooding situations, then broaden the scope by also considering behavioural factors like risk aversion. It is concluded that this approach to teaching transdisciplinary concepts for bridging engineering and behavioural science can broaden the students' understanding of sustainability and change perceptions of the barriers for more sustainable development.

Buckley et al. [4] address socially relevant projects in engineering education, concluding that students "experience greater motivation because the projects are socially relevant". Correspondingly, Jorgensen et al. [5] found that "Involving industry in the project activity raises the interest and performance of the students" and that "the real-life experience they [students] gain through the interaction with the industrial client is extremely valuable (...)". Finally, in an earlier paper presented at E\&PDE 2018 [6], also we have found that "Working interconnected with a plurality of actors from the value chain promotes reallife tasks and makes the capstone courses socially relevant. This motivates students." Thus, it seems that demonstrating relevance for the society, is a pathway for drawing the students' attention to the value of competence adding on to the technical curriculum and thus motivating them for effort.

The problem based, flipped classroom approach through a sequential assessment programme described by McWirther and Shealy [3], is paralleled by our approach to the complex in neighbourhood qualities. In the McWirther and Shealy-case, the students' scope was enrichened by the introduction of three theoretical decision-making concepts (risk aversion, regulatory focus, and take-the-best heuristic). In our case, the technical focus is enrichened through the inclusion of inhabitants' perceptions of qualities (positive and negative), identified through interviews - both taking advantages from the behavioural science.

The sequential assessment process in our neighbourhood case includes three steps. The students work in small groups, and the projects are presented in plenary (PowerPoint) so that everyone can discuss 
each other's work. The tasks have a shared focus on residential areas, from rural to urban quarters. As the students have primarily grown up in such local communities, they possess an experience that we can use as an educational entry into the planning subject. Assignment 1 is to group 4-5 houses on a given plot. The focus here is to analyse and understand the site and see the possibilities concerning terrain, vegetation, outdoor space, sun, views, etc. Assignment 3 is an extension of project 1 . The students plan a more extensive, complete residential area with homes, neighbourhoods, roads, common areas, municipal facilities, and more. The project should also demonstrate how it safeguards social qualities in this community. Assignment 2 holds the key to this project. The student's study specific residential areas. They must assess both general dispositions and the individual parts that make up the residential structure and contact the residents to get an understanding of how they perceive their living environment. In the preparation of the assignment, a social anthropologist teaches "social quality" and advise students on how to approach the residents. In addition to lectures on technical/legal subjects, we emphasise the importance of "aesthetic quality" in built environments and point to examples that demonstrate this.

\section{EXAMPLES FROM ASSIGNMENT 2}

The students initiated the project by collecting regulatory plans, maps, aerial photographs, etc. They continue with visits to the residential area to conduct on-site surveys, recording buildings/structures (outbuildings, garages, exterior walls, fences, pavements, street furniture, lighting, mail, garbage, and more.) in combination with common areas, greenery, and road designs. From a technical point of view, one seeks to understand the functional strengths and weaknesses of the built environment. From an aesthetic point of view, one tries to recognise patterns that give the place visual identity and character. As one of the aims of this project is to encourage students to learn how physical (housing) structures can have an impact on social qualities, the interviews with residents are essential. However, tact and consideration must be shown.

Here are some of the advice the students get: "Once you have made the first registrations and become acquainted with the residential area, you may want to talk to those who live there. This can give clues to things you do not see immediately - how the place works socially, things the residents are happy/dissatisfied with, something they want to change, etc. Make a list in advance of topics that you want to go through and try to remember them, so you do not have to physically find them during the conversation. Also, consider how long the conversation will take. If you get a lot of useful information from the person you are talking to, it may be worth spending a little more time than planned. Usually, a chat with 3-4 people, spending 10-15 minutes on each is sufficient to get the first glimpse into how the neighbourhood is experienced by those who live there. The answers you get should be noted (briefly) to be used in the presentation (assignment 2) to illustrate the conditions or solutions you are discussing. Those cited must be anonymised; Young lady/man with child: student: Man/pensioner etc."

Example of an interview guide:

- How would you describe the neighbourhood in a few words?

- Does it feel safe for the kids here?

- Do people know each other here?

- Do you have an overview (from your front/entrance) to the nearby playground, the neighbour's entry, passing people, - Do you feel connected to the neighbourhood?

- Are there common areas or/and informal meeting places in the residential sector?

- Are there local people taking initiatives for the good of the local community? (Social Entrepreneurs)?

- $\quad$ Are there events for everyone to attend? Like maintenance of common areas (dugnad), seasonal markings (Christmas, midsummer, etc.)

- $\quad$ Do you have a resident board?

- Do you have any kind of swap/ sharing arrangements (children's clothing, tools, ladders, carpools, etc.)?

- Are there things here that you think provides this place with an identity?

All students present the results and their analysis in a plenary session. Fig. 1 gives a small example from one presentation ( 2 slides drawn from a total of 45). After each presentation, there is a discussion in the plenary. 

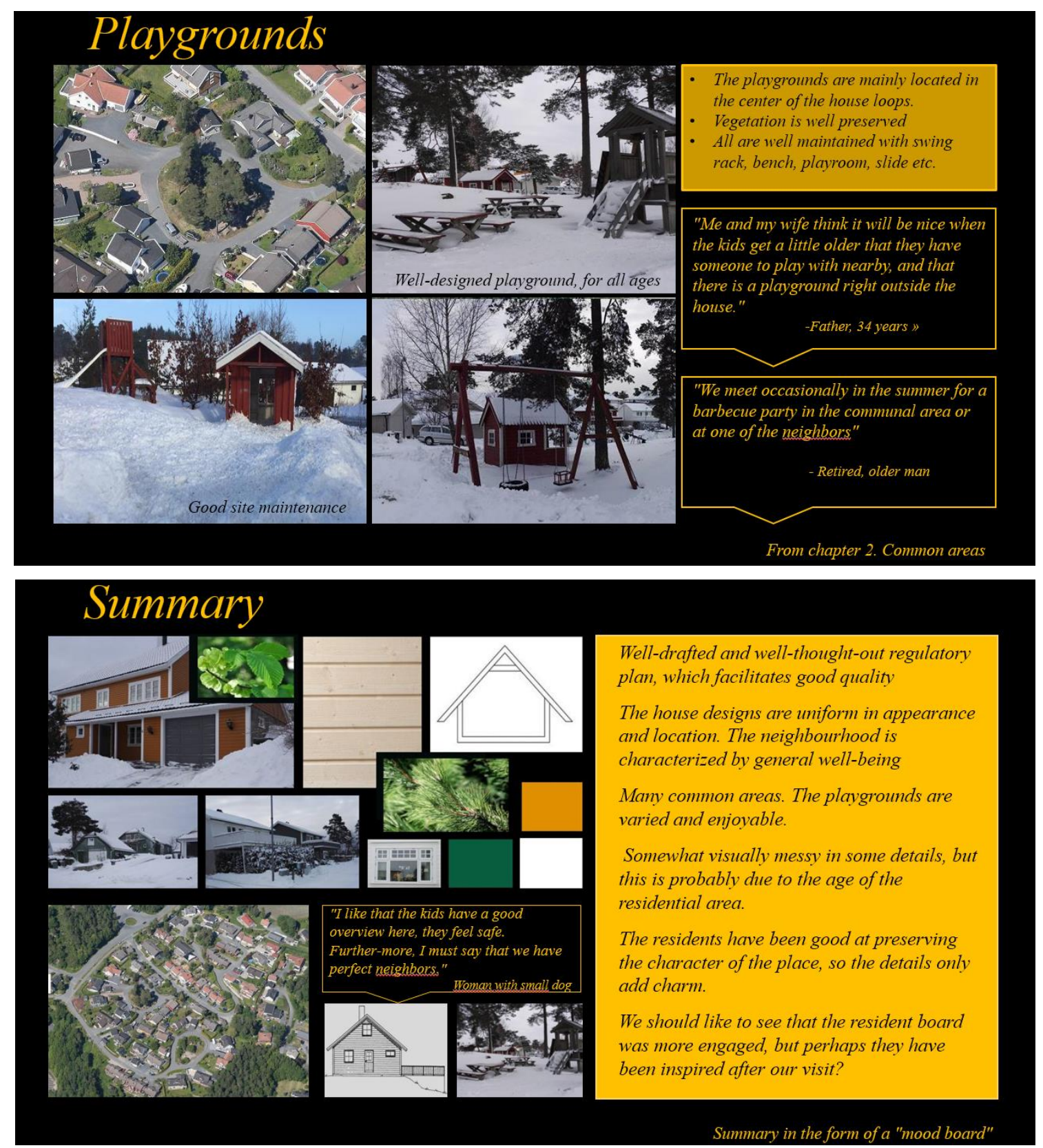

Figure 1. Examples from a student presentation of assignment 2 (2 slides drawn from a total of 45 in the presentation)

The students provide detailed descriptions and capture the characteristics of the built areas. They check the zoning plans and regulations with the built environment and point out compliance or negative deviations. They can further expand the task by investigating statistics, frequency of homes sold, neighbourhood profiles used by brokers, etc. More interesting is that they suggest physical measures or changes that can better the social environment. The conversations with the residents reveal their concerns and wishes - such as traffic safety, development of common areas, etc. The students also propose aesthetic measures to clean up the visual mess and uniformize certain elements: stone walls, fences, sidewalks, street furniture, outdoor lighting, garbage and mailbox areas, etc.

\section{Discussion}

The topic of this paper is to address how civil engineering students can be taught to grasp the more intangible factors needed for solving the complex challenges of sustainable societies, in addition to the technical skills that are traditional parts of the engineering education. For ten years, we have tested a problem-based flipped classroom approach. The students are only equipped with a minimum of formal knowledge through traditional lectures before they enter the real-life society for learning through investigating. For preparation, the initial lecturing includes lectures from behavioural sciences, given by 
a social anthropologist who teaches "social quality" and advises students on how to approach the residents.

This approach harmonises well with that presented by McWirther and Shealy in [3]. It was concluded that the students' decision-making priorities changed from the first-step assignment mainly focusing on technical issues, through the second assignment where their work where enrichened by the introduction of three theoretical decision-making concepts drawn from the social sciences. Further, that: "The student reflections also indicated that most students grasped the relevance of behavioural science to engineering decision-making, both for this case study and for sustainability in general.

Our approach also includes a third assignment after assignment 2 enrichened with tools from the social sciences. In the third assignment, students are expected to demonstrate in practice the knowledge gained from assignment 2 . We find clear indications that as students begin with assignment 3 , they have gained a deeper understanding of the residential area as a small community, including competence on what defines neighbourhood qualities and how to promote good qualities through the design of the physical environment. This is essential, as this competence is not lectured but developed by the students themselves through investigating real societies with the use of transdisciplinary tools that engineering students are normally unfamiliar with.

Hence, like McWirther and Shealy, we conclude that the approach using problem-based flipped classroom, students have developed transdisciplinary competence additional to that engineering students are normally equipped with. Initially, students often wonder what aesthetics has to do with social quality. After executing these assignments, they often conclude that a design language that is holistic and consistent is perceived as credible and predictable and thus provides a sense of security and that this perception of order and safety contributes to social quality. Hopefully, this also contributes them to becoming more conscious of their corporate social responsibility in their role as future planners - that is in their role as designers for the built environment.

In addition to the professional gaining from this approach, it is worth dwelling on the pedagogical issues. Engineering students are often thought to prefer the tangible topics characterising the engineering profession, to the more intangible topics that tend to be associated with some social sciences. Just like engineering "teachers" tend to prefer teaching the traditional tangible topics, it is easily expected that lectures on the other issues would not be well-received and reputed amongst the engineering students. In contradiction to this, the students find that the problem-based flipped classroom approach is popular amongst the students. Former students frequently present this fieldwork as the most meaningful part of their education. Though this claim is just anecdotes and not the result from structured evaluations, transferable experiences are easily found in the research literature. In the paper "Making education on sustainable community planning tangible" by Rydningen and Nordahl-Rolfsen [7], a presentation is made on an education where civil and environmental engineering students are being exposed to the use of guided study-tours as a separate learning tool to expand the knowledge gained through the more traditional lectures and exercises. From the more structured evaluation of the students' learning outcome, a typical student is quoted on "My academic progress has been pretty good. I feel like I have learned more from working with the projects than the lectures. But mostly, I have probably learned from study tours". This could easily have been a quote from one of our students after having experienced assignment 2 .

\section{CONCLUSIONS}

Based on ten years' experience of testing a problem-based flipped-classroom approach to equipping the civil engineering students with transdisciplinary skills after only basic introductory lecturing, it is concluded that:

The challenge of adding multidisciplinary competence to an already packed curriculum while still maintaining and nurturing the students' motivation for effort, is successfully approached by demonstrating the societal relevance of this multidisciplinary competence. This demonstration is revealed by the students themselves through the problem-based flipped classroom experiences.

The problem-based flipped classroom approach, achieved by extending the classroom to the residential neighbourhoods, is found to be a good approach for developing the students' transdisciplinary competence that is often rejected when taught through traditional lecturing and exercising. Students often report this real-world challenge to be the most memorable part of their education. 
Enrichening the students' tool-box with basic headline competence from social sciences in addition to the traditional tangible engineering education, improves the students' competence to understand what defines neighbourhood qualities and how to promote good qualities through the design of the physical environment. Hopefully, this also contributes them to becoming more conscious of their corporate social responsibility in their role as future planners - that is in their role as designers for the built environment. In more general terms, the transdisciplinary tools in addition to the traditional engineering competence gained through a problem-based flipped classroom approach improves the students' ability to meet the complex challenges of contributing to developing sustainable societies.

\section{REFERENCES}

[1] Bohl, C.C. "New urbanism and the city: Potential applications and implications for distressed inner-city neighbourhoods," 2000.

[2] Dhadphale, T. and Baughman, J. "Understanding characteristics of multidisciplinary collaboration using concept maps," in DS 93: Proceedings of the 20th International Conference on Engineering and Product Design Education (E\&PDE 2018), Dyson School of Engineering, Imperial College, London. September 2018, pp. 526-531.

[3] McWhirter, N. and Shealy, T. "Case-based flipped classroom approach to teach sustainable infrastructure and decision-making," International Journal of Construction Education and Research, vol. 16, no. 1, pp. 3-23, 2020.

[4] Buckley, M. Kershner, H. Schindler, K. Alphonce, C. and Braswell, J. "Benefits of using socially-relevant projects in computer science and engineering education," in Proceedings of the 35th SIGCSE technical symposium on Computer science education, 2004, pp. 482-486.

[5] Jorgensen, J.E. Mescher, A.M. and Fridley, J.L. "Industry collaborative capstone design projects," in Proceedings of the International Conference on Engineering Education, 2001, pp. 7B6-12.

[6] Thorstensen, R. Larsen, I and Svennevig, P. "Pursuing diversity in engineering education; a case study on RD\&I-cooperation within civil engineering," S. Green et al., Eds., 2018: Institution of Engineering Designers, The Design Society.

[7] Rydningen, U. and Nordahl-Rolfsen, C. "Making education on sustainable community planning tangible," WIT Transactions on Ecology and the Environment, vol. 204, pp. 789-805, 2016. 